\title{
A survey of the Australasian clinical medical physics and biomedical engineering workforce
}

\author{
W. H. Round
}

\author{
Department of Engineering, University of Waikato, Hamilton, New Zealand
}

\begin{abstract}
A survey of the medical physics and biomedical engineering workforce was carried out in 2006. 495 positions (equivalent to 478 equivalent full time (EFT) positions) were captured by the survey. Of these 268 EFT were in radiation oncology physics, 36 EFT were in radiology physics, 44 were in nuclear medicine physics, 101 EFT were in biomedical engineering and 29 EFT were attributed to other activities. The survey reviewed the experience profile, the salary levels and the number of vacant positions in the workforce for the different disciplines in each Australian state and in New Zealand. Analysis of the data identifies staffing shortfalls in the various disciplines and demonstrates the difficulties that will occur in trying to train sufficient physicists to raise staffing to an acceptable level.
\end{abstract}

Key words Workforce, medical physicists, biomedical engineers

\section{Introduction}

In order to be able to effectively plan to ensure that sufficient medical physicists and biomedical engineers will be available to meet the medical needs of the future, two elements are necessary. First there has to be a way of assessing what the needs will be in the future based on such parameters as population, the incidence of diseases and changes in technology. Second, it is important that the current size, level of training and experience and the age structure of the workforce be known. With this information it is possible to estimate how many new physicists and biomedical engineers should be trained to meet future needs. It is also important to know what the salary structures are in each jurisdiction so that adjustments can be made to salary scales to ensure that it is possible to retain the current workforce and to attract new recruits to meet the needs.

\section{The survey}

In August and September of 2006 a survey of the medical physics and biomedical engineering work force was carried out in Australia and New Zealand.

To ensure that as complete coverage of the workforce as possible would be obtained, effort was put into ensuring

\footnotetext{
Corresponding author: W. H. Round, Dept of Engineering, University of Waikato, Private Bag 3105, Hamilton, 3240, New Zealand, Tel: (64 7) 838 4173, Fax: (64 7) 8384835

Email: h.round@waikato.ac.nz

Received: 17 December 2006; Accepted: 26 February 2007

Copyright (C) 2007 ACPSEM
}

that as many as possible of the clinical medical physicist and biomedical engineer positions would be accounted for. Initially all of the Branch Chairmen of the Australasian College of Physical Scientists and Engineers in Medicine (ACPSEM) were asked to list contact details of all of the chief or principal physicists and biomedical engineers in all of the clinical departments in their branches. The lists were to contain the details of those in the private as well as the public sector, and those outside the hospital-based medical sector who may be carrying out duties such as overseeing radiological quality control that a hospital-based physicist may typically do.

The lists were to include all chief or principal physicists and biomedical engineers whether or not they were members of the ACPSEM to ensure a full coverage of the workforce.

A survey document was then emailed to each of the chief or principal physicists and biomedical engineers that asked them to provide for each of their established positions

- The jurisdiction in which they worked (i.e. New Zealand or the Australian state or territory).

- The years of relevant experience that the person had since passing their first degree.

Full-time study towards a relevant higher degree would be considered as relevant experience. Experience was recorded in the ranges 0 to 3,4 to 5,6 to 10,11 to 15,16 to 20 , and over 20 years experience. It should be noted that those with up to five years experience are considered to be 'in training' while those with six or more years experience are considered to be 'qualified'.

- The base salary or total remuneration package (TRP) of the person occupying the position.

In virtually all cases the base salary was provided, and all data was later processed on the basis that it 
was all base salary data. Salary data was not provided for only $11 \%$ of positions.

- The fraction of full time spent in each of the disciplines of radiation oncology physics, radiology physics, nuclear medicine physics and biomedical engineering.

The fraction of time spent on 'other' duties was also recorded, but the stipulation was made that if other duties such as administration were part of the duties required for one of the disciplines, then they should be recorded as part of the fraction in that discipline. Also, in situations such as where someone was primarily employed in a single discipline but carried out work in another discipline to support the primary discipline, this should be attributed to the primary discipline. For example, a radiation oncology physicist may do a small amount of radiology physics work on the imaging systems in the radiation oncology department where he or she is employed as a fulltime radiation oncology physicist. In such situations the radiology physics time should be attributed to the radiation oncology workforce.

- Whether or not the position was vacant.

If the position was vacant, the number of years of experience that would be required for that position was often given. If it wasn't given, but a suggested salary level was provided, then an estimate of the years of experience was made on the basis of salaries of others in the same department. If no salaries were provided with which such an assessment could be made, then the different vacant positions were chosen to cover the whole experience range. For example, if three positions were vacant one was taken to be 0 to 3 years experience, one was taken to be 10 to 15 years experience and one was taken to be over 20 years experience. This may not have given a precise prediction of the final outcome when positions are finally filled, but it still gave a sensible estimate of the size and experience of the workforce in a single jurisdiction.

After persistent requests, data was obtained from all relevant departments identified in the branches' lists. Most of the data was received by mid-September 2006 with the final 4\% being obtained by November 2006 .

Data was obtained for 495 positions which equated to 478 equivalent full-time (EFT) positions. Of these

- 62 EFT positions were in New Zealand

- 416 EFT positions were in Australia.

In terms of the individual disciplines

- 268 EFT positions involving 289 individual positions were in radiation oncology physics

- $\quad 37$ EFT positions involving 67 individual positions were in radiology physics

- 44 EFT positions involving 79 individual positions were in nuclear medicine physics
- 101 EFT positions involving 115 individual positions were in biomedical engineering

- 29 EFT positions were attributed to 'other'.

While the author is confident that the data for the physicist positions is a very accurate representation of the workforce at the time that data was gathered, there is doubt that the biomedical engineering data is complete. This is for two reasons.

First, it is difficult to define what an engineer actually is and this is confirmed by the various grades of engineering membership of the engineering societies such as Engineers Australia and the Institution of Professional Engineers of New Zealand. Engineers can vary in qualification from technician engineers to professional engineers. The problem does not exist with physicists where the standard that is used to determine whether or not an individual is a physicist is more universally accepted.

Second, the physics workforce is confined to a smaller number of employers who are mainly in the public sector. However a much larger proportion of the biomedical engineering workforce is in the private sector with a lot of the work that they do being let out to private contract. Thus it is a lot harder to determine the extent of the workforce.

\section{The size of the established workforce}

The workforce size data for the four disciplines is presented in Table 1.

It should be noted that the numbers quoted in the table include vacant as well as filled positions. Therefore the table provides data as to the number of established positions, and indirectly (by subtracting the quoted vacancy numbers) the actual workforce size in each jurisdiction. The vacancies tend to be for qualified medical physicists with a high level of experience rather than for younger, less qualified physicists.

The data distinguishes between qualified physicists and those in training.

While there is a shortage of medical physicists, if vacancies are to be filled without merely moving existing physicists from one established position to another, then in the short term experienced physicists must be recruited from overseas. In the longer term, more physicists must be trained to reach a steady state situation where the workforce needs are met.

\section{Radiation oncology physicist positions}

The experience level of the combined Australian and New Zealand radiation oncology physics workforce is shown in Figure 1.

There were 224 EFT and 44 EFT positions in Australia and New Zealand respectively of which 31 EFT and 6 EFT positions were vacant. This represents a vacancy rate of almost $14 \%$ in each country. While this may not seem significant, the worldwide shortage of qualified radiation oncology physicists will make it difficult to fill the vacancies by overseas recruitment. The situation will be exacerbated by the installation of more linear accelerators 
Table 1. A breakdown of the medical physics and biomedical engineering workforce in Australia and New Zealand. All numbers are in EFTs.

Medical physics and biomedical engineering workforce

\begin{tabular}{|c|c|c|c|c|c|c|c|c|c|c|}
\hline & 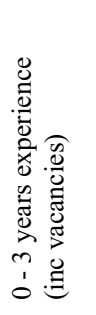 & 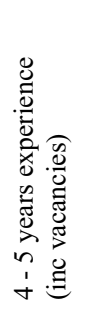 & 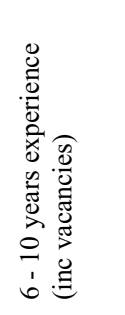 & 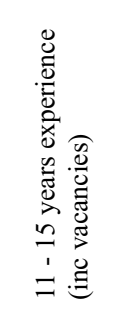 & 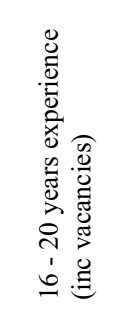 & 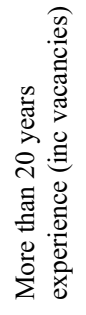 & 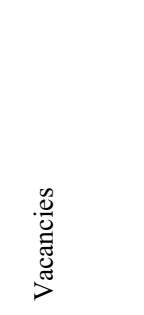 & 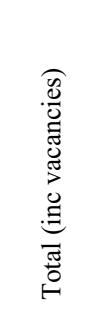 & 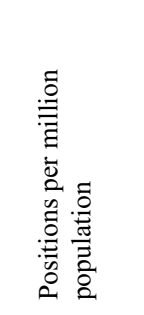 & 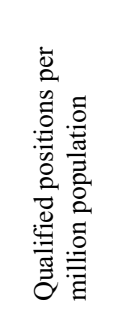 \\
\hline In training & & & Qualified & & & & & & & \\
\hline \multicolumn{11}{|c|}{ Radiation oncology physicists } \\
\hline & 0 to 3 & 4 to 5 & 6 to 10 & 11 to 15 & 16 to 20 & $>20$ & Vacancies & Total & $\begin{array}{c}\text { Physicists/ } \\
\text { million }\end{array}$ & $\begin{array}{c}\text { Physicists/ } \\
\text { million }\end{array}$ \\
\hline ACT & 0.0 & 0.0 & 2.0 & 0.1 & 1.4 & 1.0 & 0.0 & 4.5 & 14.0 & 14.0 \\
\hline QLD & 6.0 & 3.0 & 8.9 & 4.5 & 2.0 & 7.5 & 4.0 & 31.9 & 7.8 & 5.6 \\
\hline SA & 6.0 & 2.0 & 7.0 & 1.0 & 0.0 & 2.0 & 0.0 & 17.8 & 11.4 & 6.3 \\
\hline TAS & 2.0 & 0.0 & 0.0 & 0.0 & 0.0 & 4.1 & 1.0 & 6.1 & 12.4 & 8.4 \\
\hline VIC & 6.0 & 7.0 & 8.0 & 7.0 & 11.0 & 9.3 & 7.0 & 48.3 & 8.8 & 6.4 \\
\hline WA & 2.4 & 3.4 & 5.0 & 2.3 & 0.0 & 2.3 & 2.0 & 15.4 & 7.5 & 4.6 \\
\hline Total Australia & 45.3 & 28.4 & 57.3 & 36.1 & 22.9 & 34.1 & 31.0 & 223.9 & 10.7 & 7.2 \\
\hline $\mathrm{NZ}$ & 8.5 & 2.0 & 14.8 & 5.0 & 6.8 & 6.8 & 6.0 & 43.9 & 10.4 & 7.9 \\
\hline \multicolumn{11}{|c|}{ Radiology physicists } \\
\hline & 0 to 3 & 4 to 5 & 6 to 10 & 11 to 15 & 16 to 20 & $>20$ & Vacancies & Total & $\begin{array}{c}\text { Physicists/ } \\
\text { million }\end{array}$ & $\begin{array}{c}\text { Physicists/ } \\
\text { million }\end{array}$ \\
\hline $\mathrm{ACT}$ & 0.0 & 0.0 & 0.5 & 0.0 & 0.0 & 0.0 & 0.5 & 0.5 & 1.6 & 1.6 \\
\hline NSW & 0.0 & 0.0 & 0.0 & 1.1 & 0.0 & 3.4 & 1.0 & 4.5 & 0.7 & 0.7 \\
\hline QLD & 3.0 & 2.0 & 0.0 & 3.2 & 2.0 & 1.6 & 0.0 & 11.8 & 2.9 & 1.7 \\
\hline SA & 0.0 & 0.0 & 0.0 & 0.0 & 0.0 & 0.5 & 0.0 & 0.5 & 0.3 & 0.3 \\
\hline TAS & 0.0 & 0.0 & 0.0 & 0.2 & 0.3 & 0.0 & 0.1 & 0.5 & 1.0 & 1.0 \\
\hline Total Australia & 5.0 & 3.6 & 0.5 & 7.4 & 3.4 & 7.1 & 1.6 & 27.0 & 1.3 & 0.9 \\
\hline $\mathrm{NZ}$ & 1.5 & 0.0 & 1.2 & 2.8 & 0.4 & 3.4 & 0.0 & 9.2 & 2.2 & 1.8 \\
\hline \multicolumn{11}{|c|}{ Nuclear medicine physicists } \\
\hline & 0 to 3 & 4 to 5 & 6 to 10 & 11 to 15 & 16 to 20 & $>20$ & Vacancies & Total & $\begin{array}{c}\text { Physicists/ } \\
\text { million }\end{array}$ & $\begin{array}{c}\text { Physicists/ } \\
\text { million }\end{array}$ \\
\hline ACT & 0.0 & 0.0 & 0.5 & 0.1 & 0.0 & 0.0 & 0.5 & 0.6 & 1.9 & 1.9 \\
\hline NSW & 3.0 & 2.0 & 4.9 & 3.8 & 1.0 & 7.1 & 1.0 & 21.8 & 3.2 & 2.4 \\
\hline QLD & 1.0 & 0.0 & 0.1 & 0.3 & 1.0 & 1.1 & 0.0 & 3.5 & 0.9 & 0.6 \\
\hline SA & 1.1 & 0.1 & 0.1 & 0.1 & 0.0 & 3.7 & 0.0 & 4.9 & 3.1 & 2.4 \\
\hline TAS & 0.0 & 0.0 & 0.0 & 0.1 & 0.0 & 0.1 & 0.0 & 0.2 & 0.4 & 0.4 \\
\hline VIC & 0.0 & 0.3 & 0.0 & 0.7 & 1.1 & 2.2 & 0.0 & 4.2 & 0.8 & 0.7 \\
\hline WA & 1.4 & 2.4 & 1.0 & 0.0 & 1.8 & 0.3 & 1.0 & 6.9 & 3.3 & 1.5 \\
\hline Total Australia & 6.5 & 4.7 & 6.6 & 5.0 & 4.9 & 14.4 & 2.5 & 42.0 & 2.0 & 1.5 \\
\hline $\mathrm{NZ}$ & 0.5 & 0.1 & 0.4 & 0.0 & 0.8 & 0.3 & 0.2 & 2.1 & 0.5 & 0.4 \\
\hline \multicolumn{11}{|c|}{ Biomedical engineers } \\
\hline & 0 to 3 & 4 to 5 & 6 to 10 & 11 to 15 & 16 to 20 & $>20$ & Vacancies & Total & $\begin{array}{c}\text { Physicists/ } \\
\text { million }\end{array}$ & $\begin{array}{c}\text { Physicists/ } \\
\text { million }\end{array}$ \\
\hline ACT/NSW & 1.5 & 1.0 & 4.4 & 2.6 & 0.9 & 2.3 & 1.0 & 12.7 & 1.8 & 1.4 \\
\hline QLD & 3.0 & 3.0 & 2.0 & 0.0 & 0.0 & 2.3 & 0.0 & 10.3 & 2.5 & 1.0 \\
\hline SA & 3.0 & 4.0 & 6.0 & 0.0 & 1.0 & 3.0 & 0.0 & 17.0 & 10.9 & 6.4 \\
\hline TAS & 0.0 & 0.0 & 0.0 & 0.0 & 0.0 & 0.0 & 0.0 & 0.0 & 0.0 & 0. \\
\hline VIC & 3.0 & 3.0 & 5.0 & 10.2 & 6.6 & 8.0 & 2.0 & 35.7 & 6.5 & 5.4 \\
\hline WA & 2.0 & 1.7 & 1.0 & 2.0 & 4.0 & 9.4 & 1.0 & 20.1 & 9.7 & 7.9 \\
\hline Total Australia & 12.5 & 12.7 & 18.4 & 14.7 & 12.5 & 24.9 & 4.0 & 95.7 & 4.6 & 3.4 \\
\hline $\mathrm{NZ}$ & 0.0 & 0.0 & 1.0 & 0.8 & 0.4 & 2.8 & 0.0 & 4.9 & 1.2 & 1.2 \\
\hline
\end{tabular}




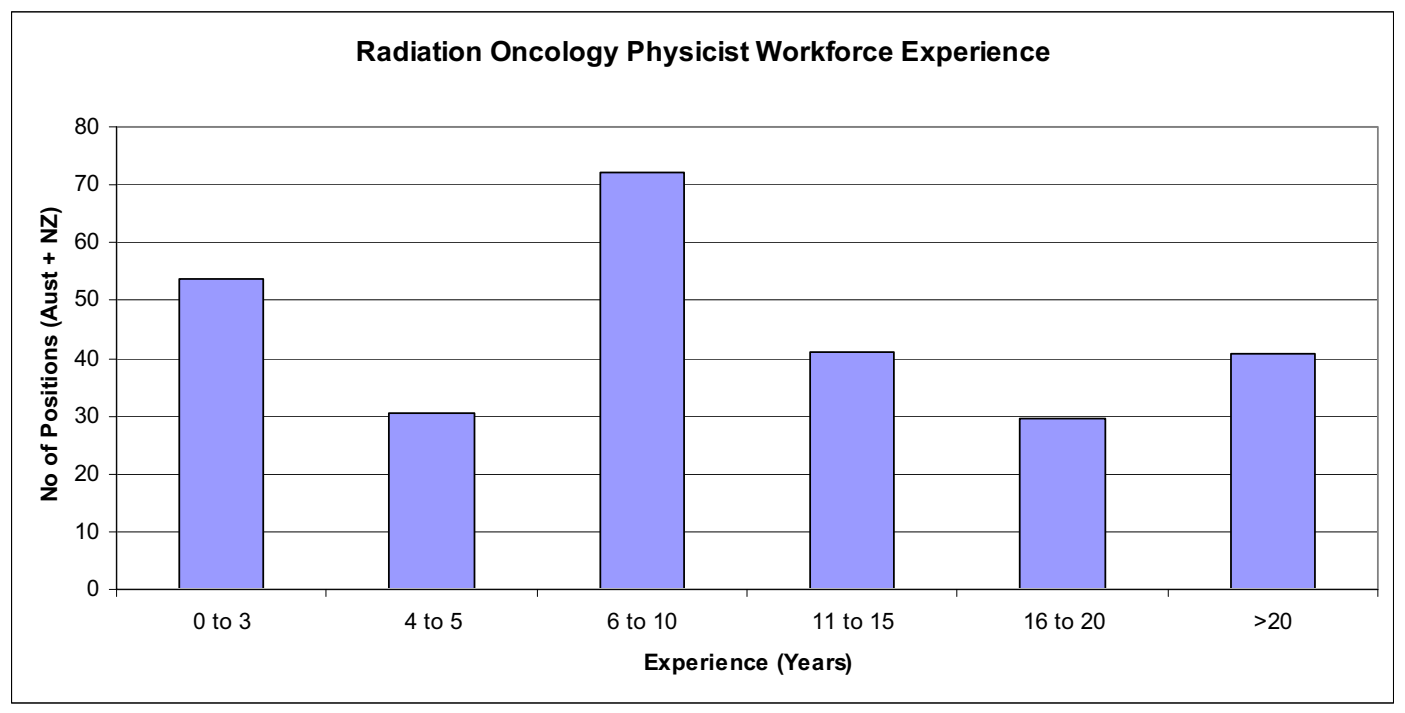

Figure 1. The experience level of the Australian and New Zealand radiation oncology physics workforce.

in each country to meet the growing demand for radiation oncology services.

There are approximately 113 linear accelerators installed in Australia and 20 in New Zealand. Using a figure of 1.7 qualified radiation oncology physicists per linear accelerator that is now a widely accepted guideline, there would need to be 192 and 34 medical physicists who are clinically qualified in radiation oncology physics in Australia and New Zealand respectively.

Care must also be used in applying 1.7 qualified physicists per linear accelerator. This is a simplification of the more complicated ACPSEM Formula $2000^{1}$ that must be used when assessing the physicist needs of an individual department. The simpler formula can only be used when averaging over a large number of departments such as on a national or jurisdiction-wide basis and not applied to individual hospitals where the need may be higher. For example, if specialized techniques such as brachytherapy or radiosurgery are practiced in a small department, then the simple formula will grossly underestimate the staffing requirements. Further, with the introduction of more technical and physics-intensive techniques such as IGRT, Formula 2000 must be reassessed to take into account the increased physics input.

With a $14 \%$ vacancy rate and the numbers of physicists with more than five years experience being as in Table 1, then the number of qualified radiation oncology physicists in Australia is 130 and in New Zealand is 29. Thus there is a shortfall from the recommended levels of 62 (or 32\%) qualified radiation oncology physicists in Australia and 5 (or 15\%) in New Zealand.

It is also generally accepted that there should be 0.5 trainee radiation oncology physicists per linear accelerator. In a steady state situation, where there is no shortage in the radiation oncology physicist workforce and the number of linear accelerators is the same as current levels, there should be 57 radiation oncology physicists in training in Australia and 10 in New Zealand. The survey has identified 73.7 EFT positions for radiation oncology physicists with less than 5 years experience in Australia and 10.5 positions in New Zealand, however not all were filled. This suggests that there are currently more trainee positions available than are required. However, not all positions were filled and a steady state situation does not exist. While there is a shortage in the qualified physicist workforce that needs to be overcome, the number of trainee physicists needs to be considerably higher than 0.5 trainee radiation oncology physicists per linear accelerator to ensure that the required number of qualified physicists is eventually met. In addition, increasing referral rates and the increasing number of accelerators being installed increases the need for qualified radiation oncology physicists which increases the need for trainees. In a situation where there is an international shortage the number of trainees must be higher yet to overcome the tendency for qualified physicists to move overseas to better paid positions with better working conditions, more advanced technology and considerable research opportunities.

Of special note is the wide variation in the number of radiation oncology physicist positions per million population from jurisdiction to jurisdiction. A variation of $2: 1$ over the jurisdictions is surprising and indicates acute shortages in some jurisdictions.

\section{Radiology physicist positions}

The experience level of the workforce is indicated for the combined Australian and New Zealand radiology physicist workforce is shown in Figure 2.

Again the number of physicist positions per million population varies considerably from jurisdiction to jurisdiction, but in this case by a factor of $10: 1$. In jurisdictions where the need for physics oversight of imaging equipment is well recognized and established, the relative number of physicists is more appropriate, but clearly some jurisdictions are underserviced. As legislation requiring physics oversight of radiology equipment is introduced by more jurisdictions, the need to train radiology physicists will become quite acute. In jurisdictions such as 


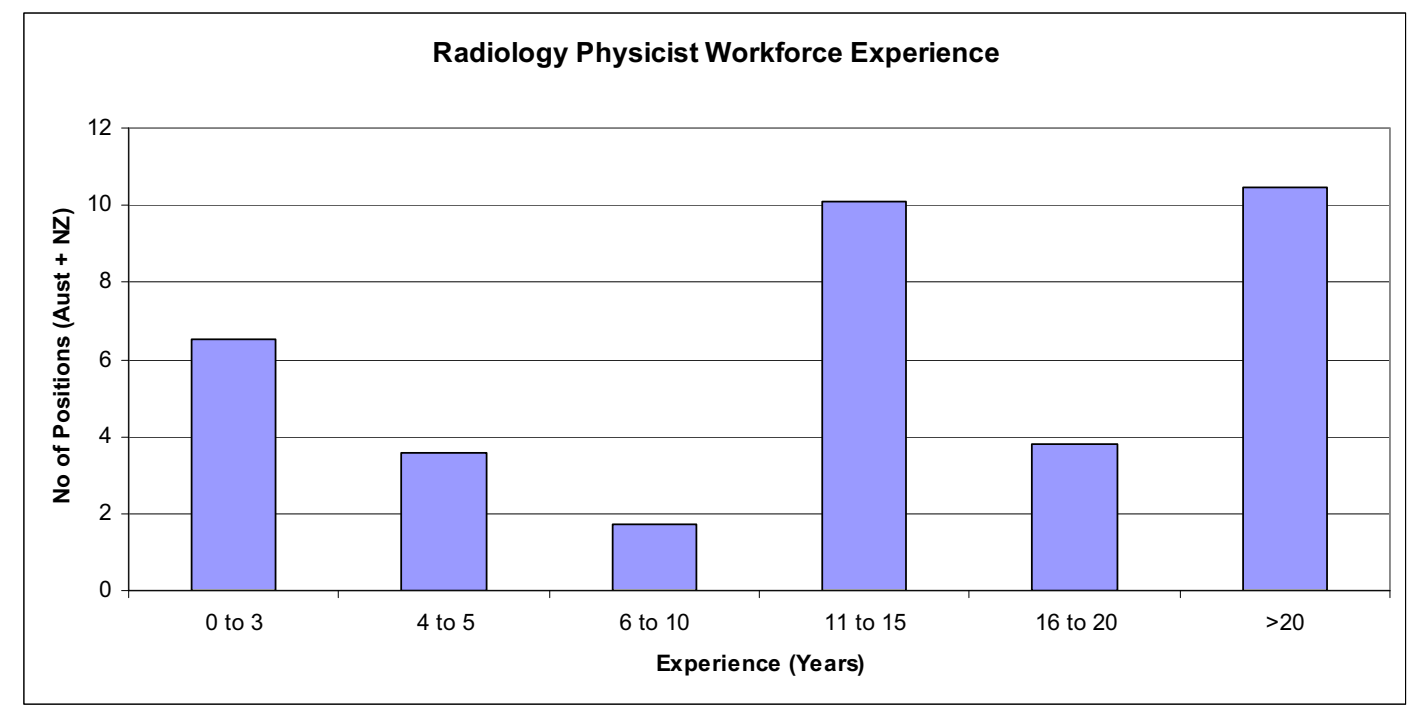

Figure 2. The experience level of the Australian and New Zealand radiology physics workforce.

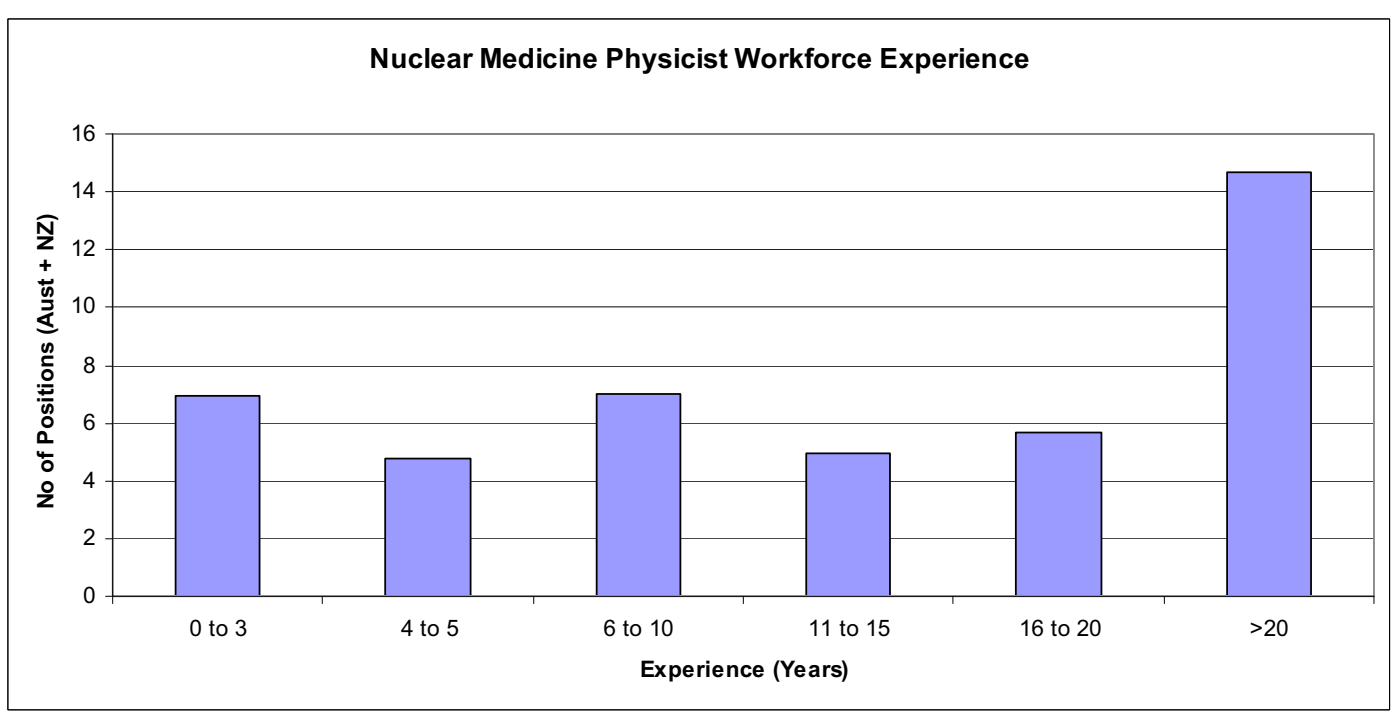

Figure 3. The experience level of the Australian and New Zealand nuclear medicine physics workforce.

Western Australia and Queensland where work has been progressing towards a more adequate radiology physics service, junior physicists are being trained to meet the needs. But it is highly disturbing that in the other jurisdictions the workforce numbers are very low and even then the physicists involved tend to be at the more senior end of the scale. This is a very serious situation. It is imperative that trainee positions are established in these jurisdictions to ensure that future needs are met.

However the opportunities for training are quite limited. The survey identified only 25 physicists with more than 5 years experience (and thus may be considered to be 'qualified') in all Australasia who are employed 0.4 EFT or more in radiology physics. This is the absolute bare minimum experience level and time commitment that one could conceivably have to be considered to be capable of training a junior radiology physicist. Two of these physicists are private providers and are unlikely to be willing to input time into training.
Also the radiology physicists who are capable of training another physicist according to these criteria are employed by only 11 Australian and 5 New Zealand providers. Of the 16 providers, two are private and are unlikely to want to be involved in training and 5 are already involved in training and may not be able to take on any further junior radiology physicists. Thus there are probably only 9 providers in Australasia who may have the spare capacity and capability to start to train more junior physicists.

It is vital that a strategy to recruit and train radiology physicists is devised and then funded if the shortfall is to be remedied and a radiology physics workforce capable of sustaining itself and training juniors is to be established.

\section{Nuclear medicine physicist positions}

The experience level of the combined Australian and New Zealand nuclear medicine physicist workforce is shown in Figure 3. 
Table 2. Recommended and actual sizes of the medical workforce in Germany, Australia and New Zealand.

Qualified physicists per million population

\begin{tabular}{lccccc}
\hline & $\begin{array}{c}\text { Germany } \\
\text { Recommended }\end{array}$ & $\begin{array}{c}\text { Australia } \\
\text { Actual }\end{array}$ & $\begin{array}{c}\text { Australia } \\
\text { Recommended }\end{array}$ & $\begin{array}{c}\text { New Zealand } \\
\text { Actual }\end{array}$ & $\begin{array}{c}\text { New Zealand } \\
\text { Recommended }\end{array}$ \\
\hline Radiation oncology & 8.5 & 7.2 & 9.2 & 7.9 & 8.1 \\
Nuclear medicine & 3.2 & 0.9 & & 1.8 & \\
Radiology & 6.4 & 1.5 & & 0.4 & \\
\hline
\end{tabular}

It is somewhat surprising that the size of the nuclear medicine physicist workforce is larger than that of the radiology physicist workforce as the number of radiology imaging units is so much larger than the number of nuclear medicine units. This possibly indicates a severe lack of radiology physicists.

The number of nuclear medicine physicist positions per million population varied from jurisdiction to jurisdiction by a factor of $8: 1$ indicating that some jurisdictions have a severe shortage of nuclear medicine physics expertise.

The disturbing feature of the workforce is the very high proportion of the workforce who have more than 20 years experience. This indicates a bias towards older physicists being involved in the discipline, and indicates that there is an urgent need to train more younger physicists. The lack of physicists with less than 10 years experience in some jurisdictions clearly demonstrates that there has been no consideration given to training the next generation of nuclear medicine physicists. Further evidence of the age imbalance is reflected in the salary levels in relation to the level of experience of the physicists. This is dealt with elsewhere in this paper.

\section{An international comparison of the medical physics workforces}

Detailed studies of medical physics workforces are few, and it is valuable to compare the Australasian situation to that of countries of a similar socioeconomic status.

In 2002 the German Society for Medical Physics published a workforce analysis that details the actual size and the expected size of the workforce ${ }^{2}$. The length of training post secondary school to become a qualified medical physicist in Germany is similar to that required in Australasia (approximately eight years) ${ }^{3}$. The study categorizes physicists into those involved in radiation oncology physics, radiology physics, nuclear medicine physics and radiation protection while the survey reported here distributed the radiation protection aspect of physicists' duties into the other three categories directly. By taking the data from the German survey and distributing the radiation protection workforce through the other three categories in proportion to the size of the reported workforce in those categories, a sensible comparison is able to be made between the Australasian and the German workforces. The comparison is given in Table 2 .

The actual workforces in the table for Australia and New Zealand include vacant positions. The German survey was not so robust in capturing the entire medical physics workforce as in the survey reported here, so the actual workforce size is not reported here. However the German report indicated that there was a substantial deficit in the workforce in all disciplines.

The recommended radiation oncology workforces for Australia and New Zealand were calculated on the basis of 1.7 qualified radiation oncology physicists per linear accelerator, the actual number of linear accelerators and the population. It is seen that the recommended per capita sizes of the qualified radiation oncology physicist workforces in Australia and New Zealand are similar to the recommended size for Germany, although in all three countries the actual number of positions is less than that.

Recommended levels for the nuclear medicine and radiology physics workforces in Australia and New Zealand have not yet been developed. However, it is seen from the table that the workforce numbers in these disciples in Australia and New Zealand are substantially lower than those recommended in Germany. Clearly the Australian and New Zealand nuclear medicine and radiology physics workforces must be increased with some urgency.

\section{Biomedical engineering positions}

The experience level of the combined Australian and New Zealand biomedical engineer workforce is shown in Figure 4.

As has been indicated, the biomedical engineering workforce is difficult both to define and to survey. Again there is a large proportion of engineers with more than 20 years experience, but the proportion with less than ten years experience indicates that younger engineers are moving into the profession. The relative numbers of biomedical engineers per million population again varies considerably from jurisdiction to jurisdiction, but this may be a reflection of the proportion of biomedical engineering done under private contract which is harder to account for than that done in the public service.

\section{Salaries}

The salary data analyzed here is that of medical physicists and biomedical engineers actually employed and does not include vacant positions. It is weighted according to the EFT of each position. One physicist's salary was left out of the analysis as that person, while acting as a medical physicist and biomedical engineer, is actually employed on a non-physicist salary scale. 


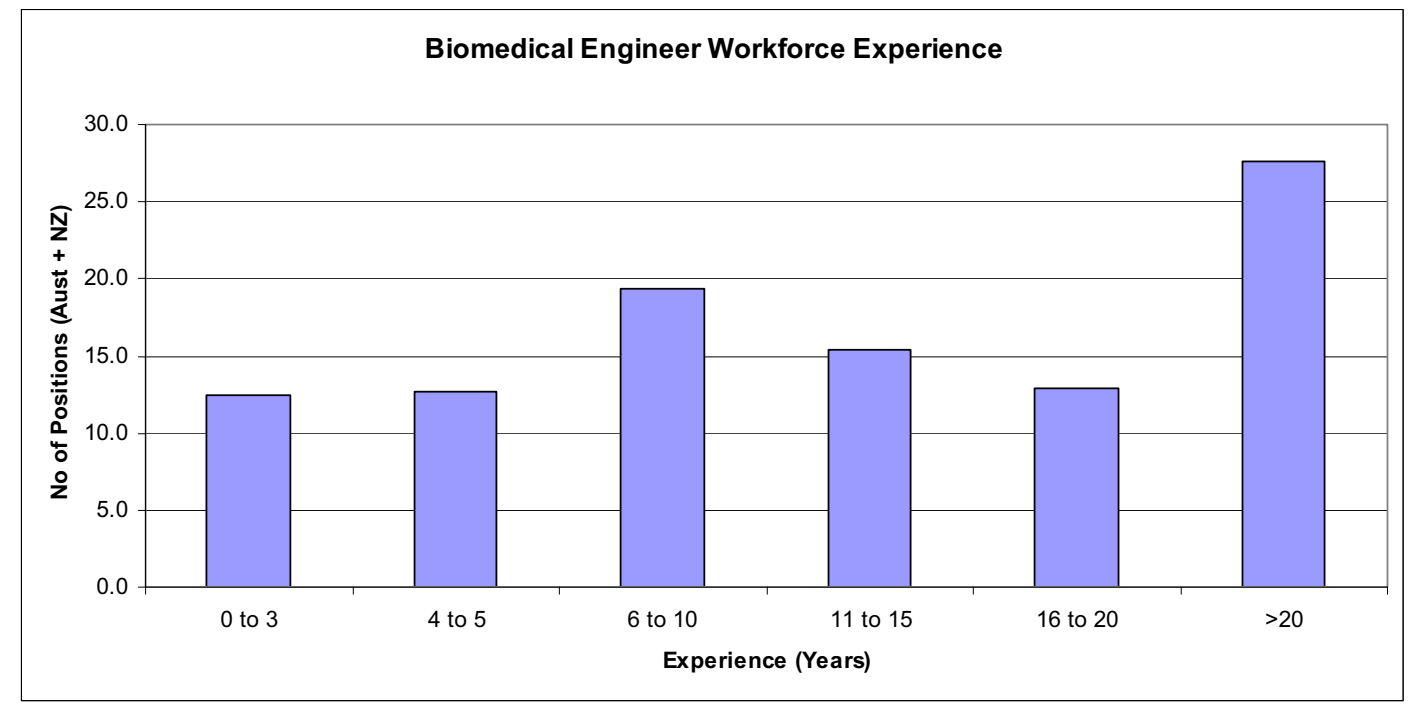

Figure 4. The experience level of the Australian and New Zealand biomedical engineer workforce.

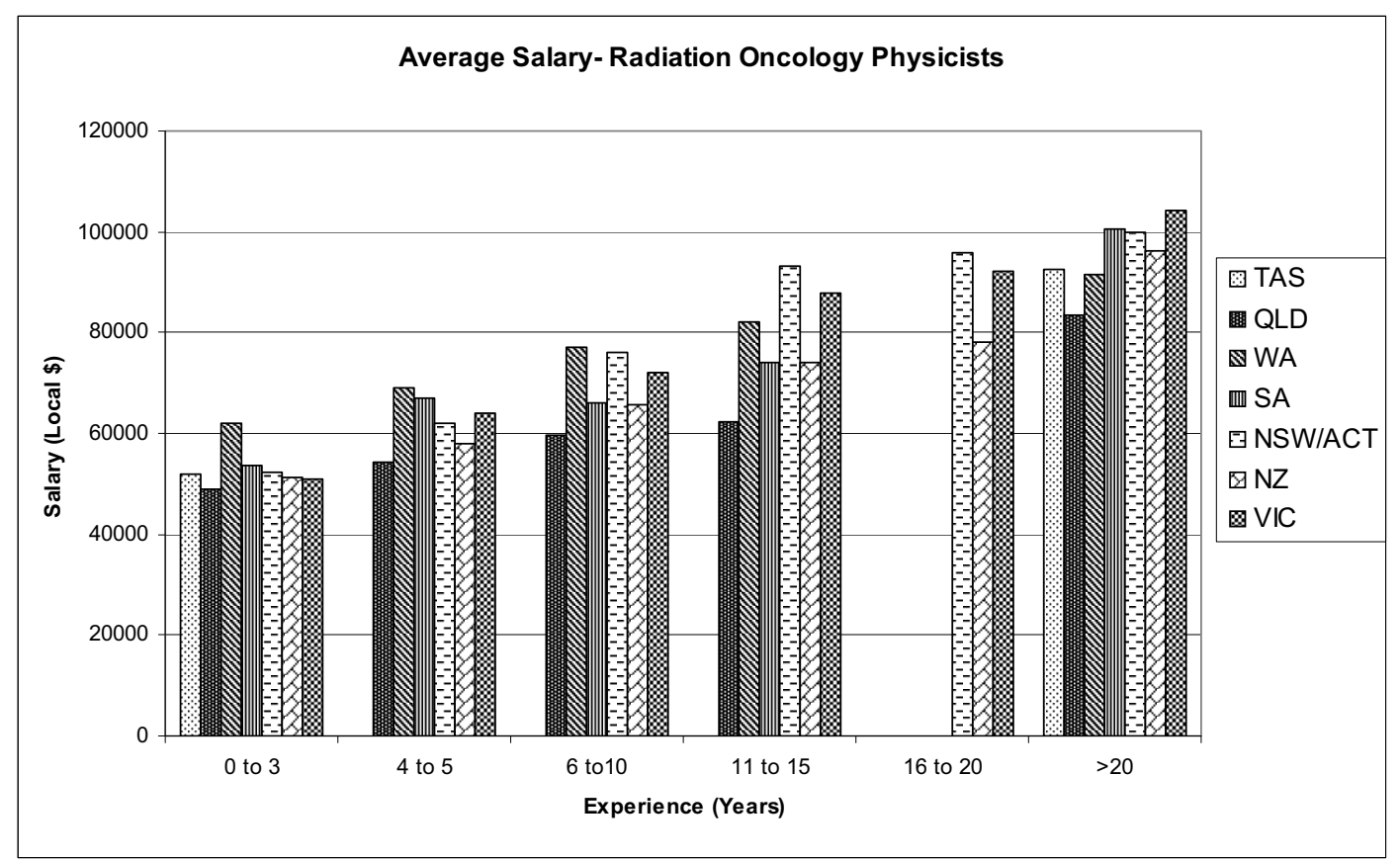

Figure 5. The average salaries of radiation oncology physicists in different jurisdictions for different levels of experience.

\section{Radiation oncology physicists}

Figure 5 shows the average salaries in each jurisdiction. The average salary varies from jurisdiction to jurisdiction at each level of experience and, although this is not shown, also varies considerably within each jurisdiction. It is notable that the salaries of the least experienced physicists are highest in Western Australia, but at the most senior levels this is not so. At the more senior levels the salaries are highest in New South Wales and Victoria, even though there is a special salary loading for the radiation oncology physicists in Western Australia. Of special note, the salaries in Queensland lag considerably behind those in the other jurisdictions.

There is a difference in the average salary levels in
Australia and New Zealand. This is demonstrated in Figure 6 where there is a definite tendency for the salaries (in local dollars) to be higher in Australia at all levels except for the most experienced levels when there is parity between the two countries.

\section{Radiology physicists}

Figure 7 shows the average salaries for radiology physicists in Australia and New Zealand. A figure showing the salaries from jurisdiction to jurisdiction is not provided as the number of physicists involved is quite small. However, average salaries are higher in Australia than in New Zealand. It is notable that there are no radiology physicists employed in Australia with 6 to 10 years of 


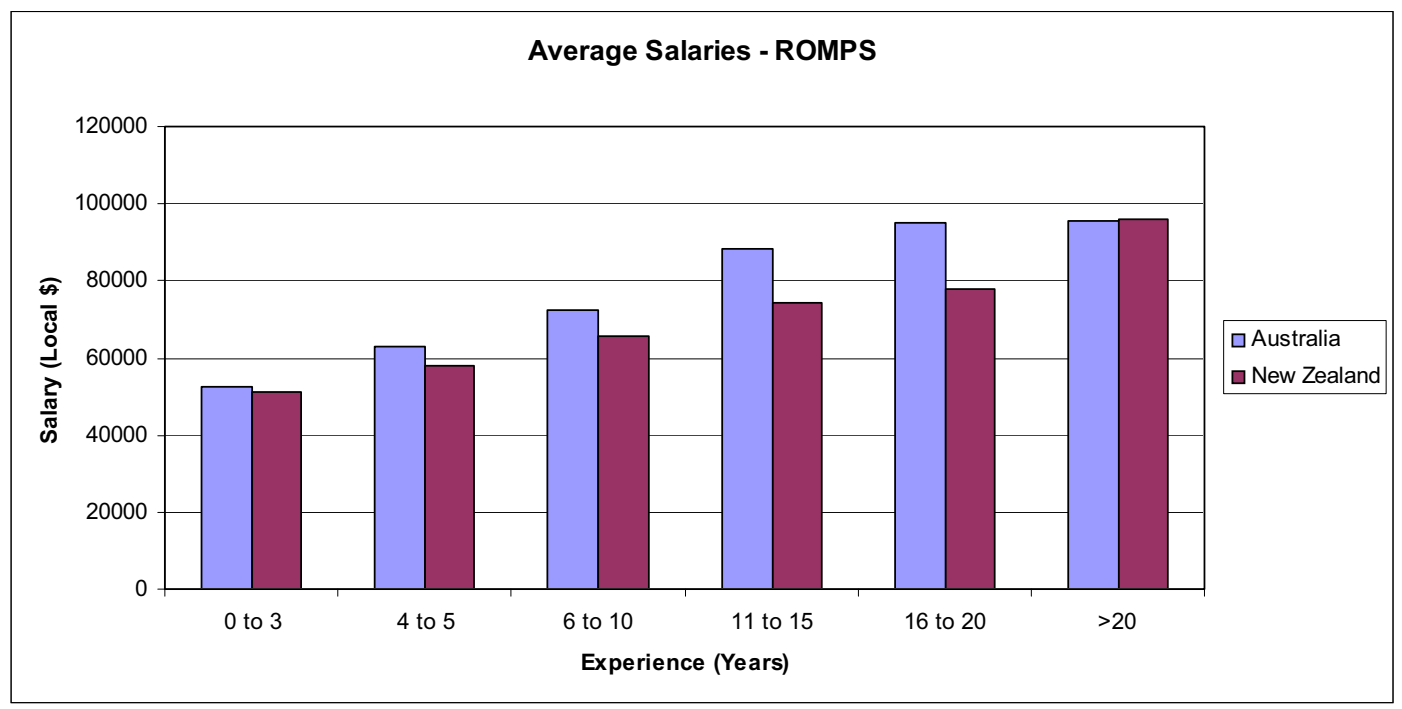

Figure 6. The average salaries of radiation oncology physicists in Australia and New Zealand for different levels of experience.

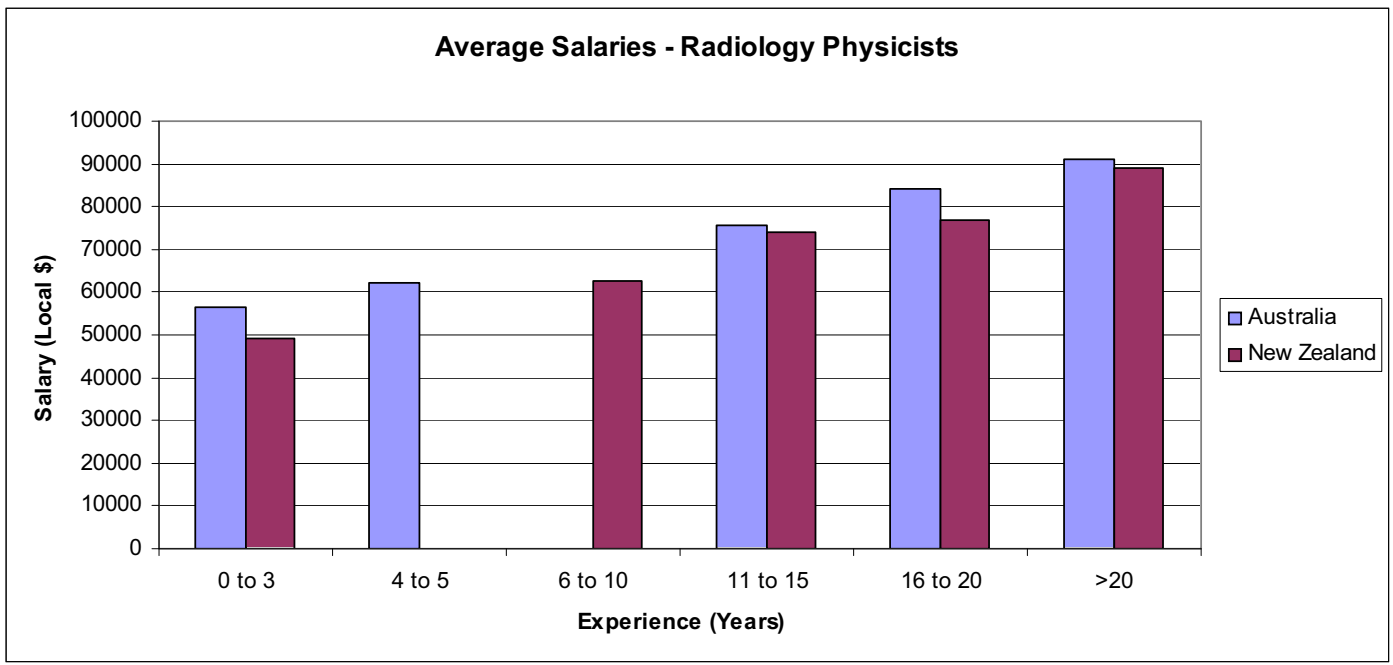

Figure 7. The average salaries of radiology physicists in Australia and New Zealand for different levels of experience.

experience, although there is one 0.5 EFT vacant position for such a person in one jurisdiction.

\section{Nuclear medicine physicists}

Figure 8 shows the average salaries for nuclear medicine physicists in Australia and New Zealand.

A figure showing the salaries from jurisdiction to jurisdiction is not provided as the number of physicists involved is quite small. However, the average salaries are higher in Australia than in New Zealand. It is notable that physicists in Australia in the 6 to 10 year experience range are highly paid compared to their more senior counterparts. This may be due to market forces reacting to the lack of nuclear medicine physicists and confirms the need discussed earlier to train more nuclear medicine physicists to replace the more senior physicists in years to come as they leave the workforce.

\section{Biomedical engineers}

Figure 9 shows the average salaries of biomedical engineers in the different jurisdictions. There is a surprisingly large variation in the salary levels for each level of experience although the variation tends to lessen at the more senior levels.

Figure 10 shows the average salaries for biomedical engineers in Australia and New Zealand. The average salaries are higher in Australia than in New Zealand. There appears to be a need to enhance the junior biomedical engineer workforce in New Zealand as the survey has not revealed any biomedical engineers in the 0 to 5 year experience range.

\section{Salaries across disciplines}

Figure 11 provides a comparison of the average salaries in Australia of the different disciplines. The career path 


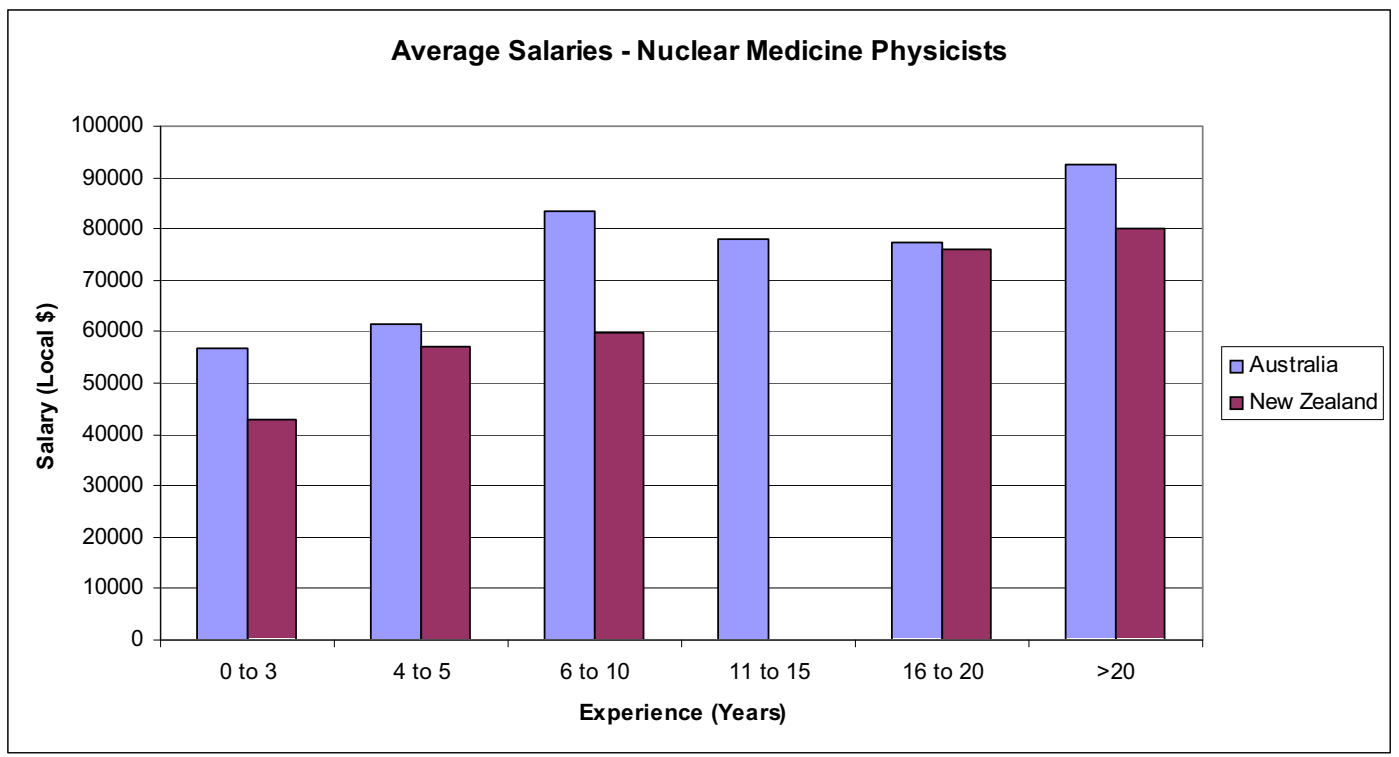

Figure 8. The average salaries of nuclear medicine physicists in Australia and New Zealand for different levels of experience.

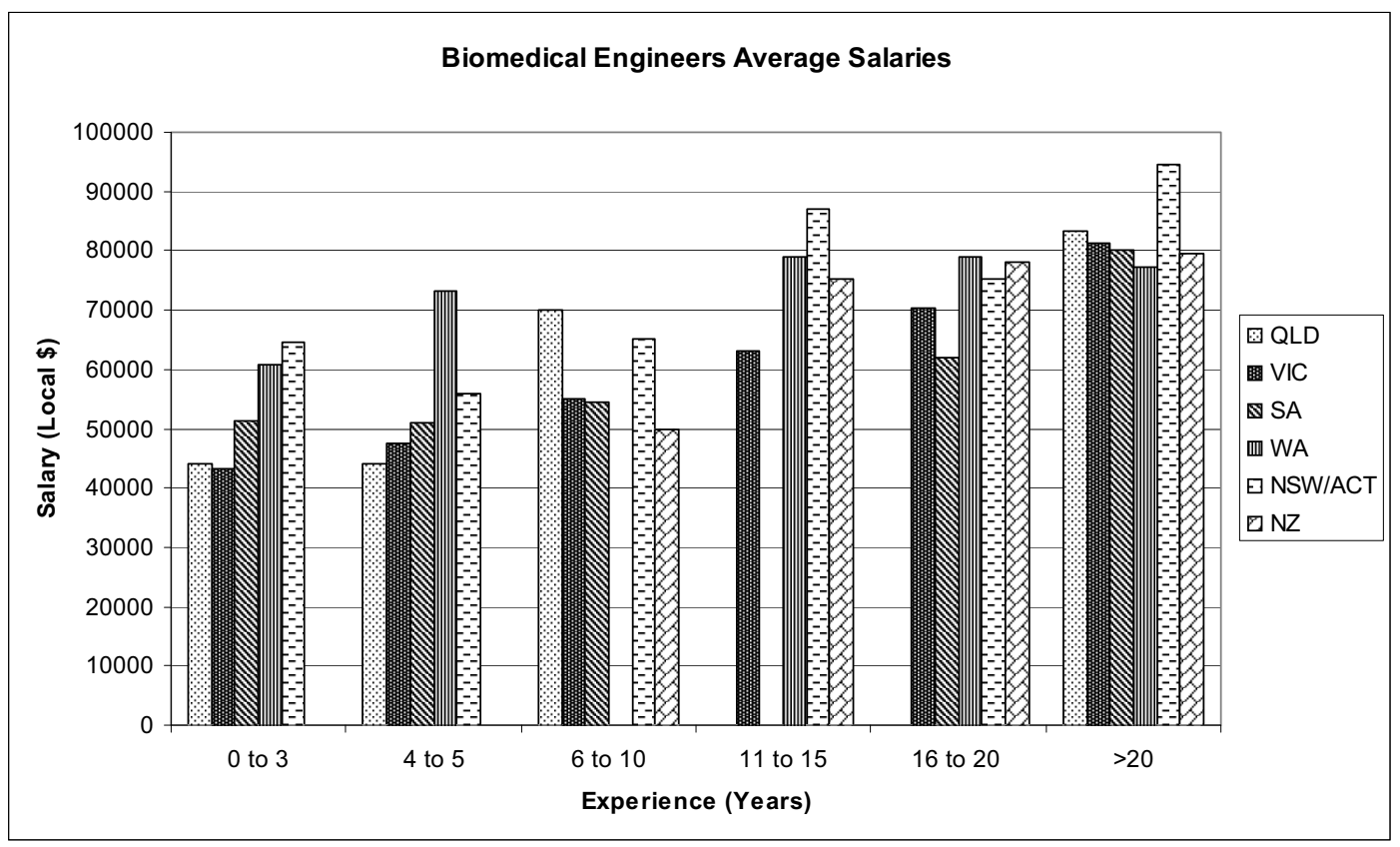

Figure 9. The average salaries of biomedical engineers in different jurisdictions for different levels of experience.

seems to be similar across the disciplines apart from the generally higher salaries being achieved by the radiation oncology physicists and the higher than usual salaries being paid to the nuclear medicine physicists with six to ten years experience.

Figure 12 provides a comparison of the average salaries in New Zealand of the different disciplines. The career path seems to be similar across the disciplines. In general the highest salaries are achieved by radiation oncology physicists with the nuclear medicine physicists being paid the least. However, it should be noted that the medical physics and biomedical engineering workforce in New
Zealand is quite small and the average salaries have generally been calculated on small numbers of individuals and therefore the data may not be sufficient to draw valid conclusions.

\section{Discussion}

The survey is probably the most definitive survey of the medical physics and biomedical engineering workforce in Australia and New Zealand carried out to date. The data collection method will have captured almost all the physics 


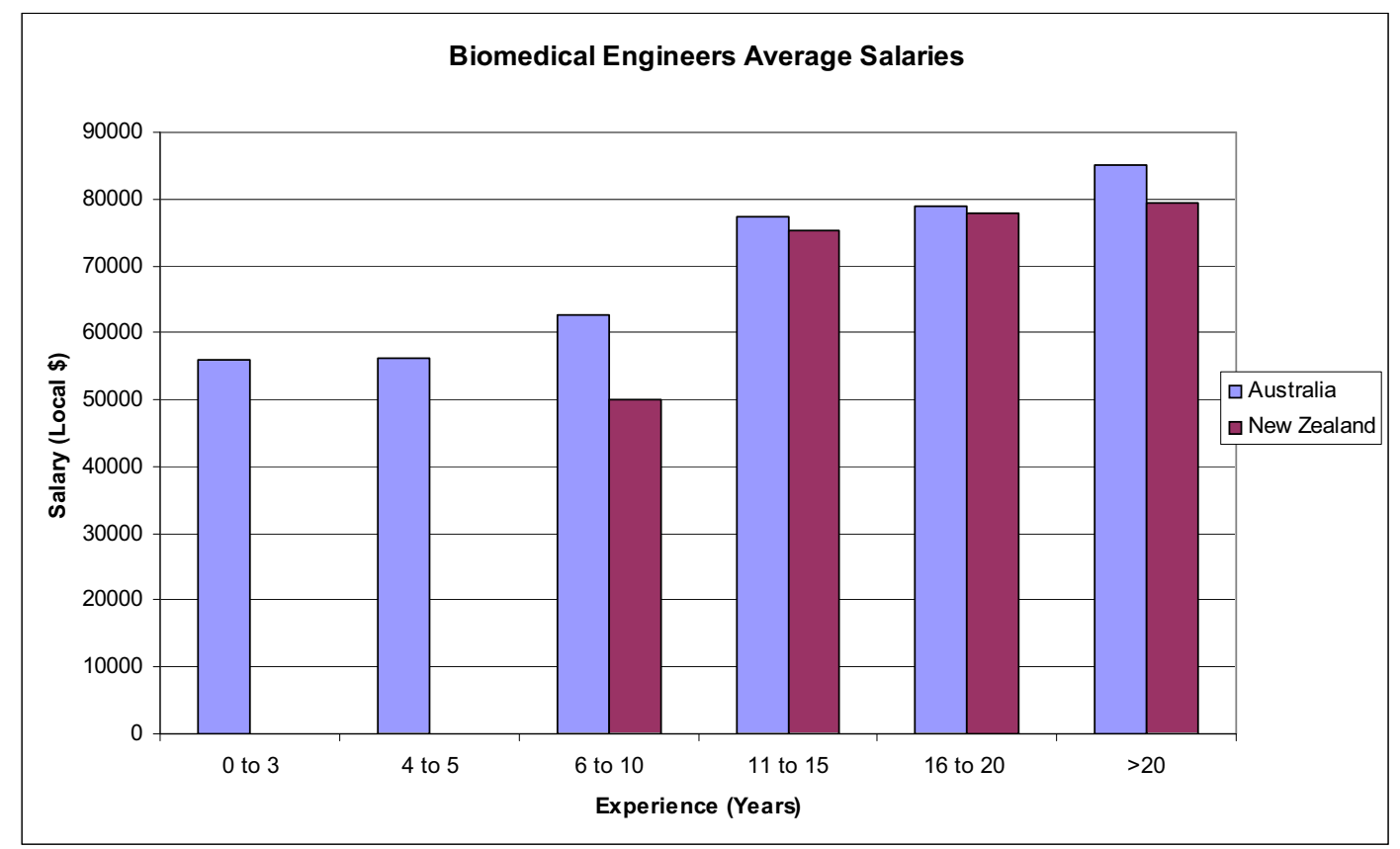

Figure 10. The average salaries of biomedical engineers in Australia and New Zealand for different levels of experience.

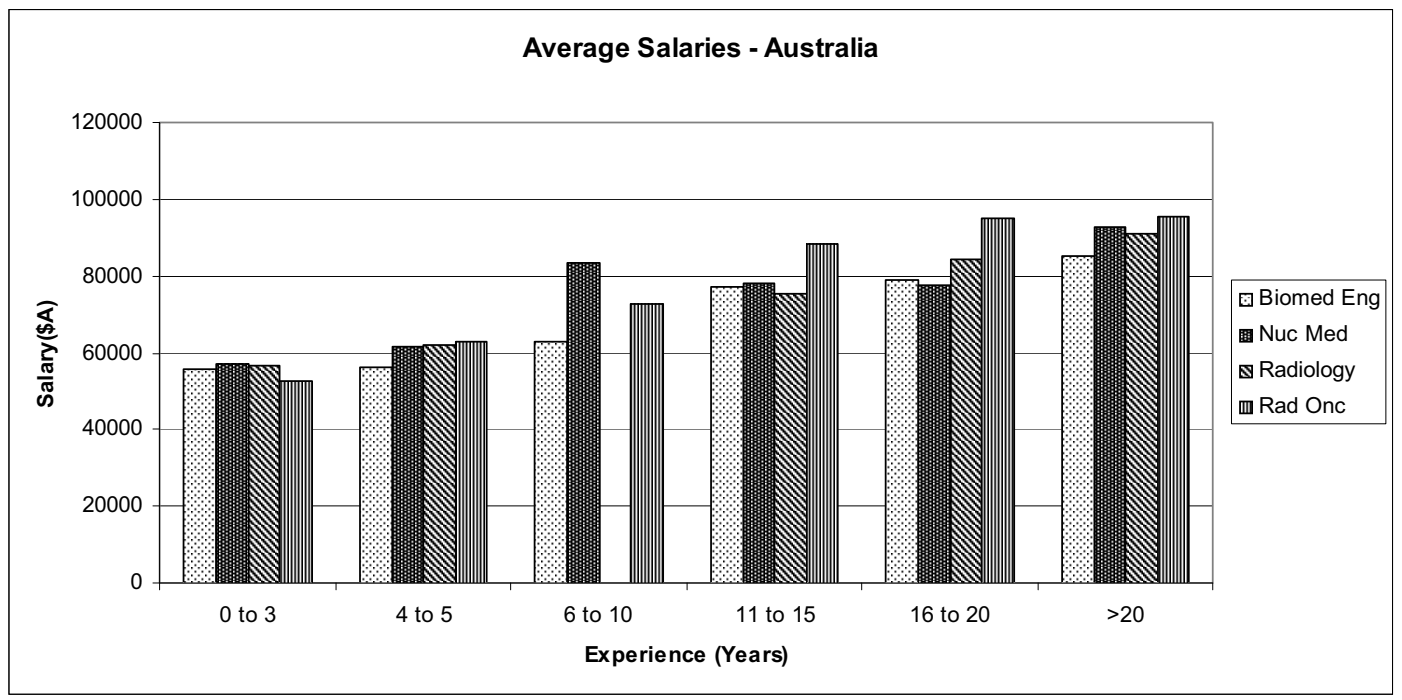

Figure 11. The average salaries of the various disciplines in Australia.

workforce, but is likely to have not captured a significant proportion of the biomedical engineering workforce.

\section{Radiation oncology physics}

The relatively large number of radiation oncology physicists makes it possible to make a reliable analysis of this part of the workforce. It is clear that there is a large deficit in the number of qualified physicists to ensure that the needs of the radiation oncology services are met. The position vacancy rate is approximately $14 \%$ and the number of positions established falls short of the recommended levels resulting in a large overall shortage.

It is especially disturbing that in some jurisdictions the number of physicists per million population is small and needs to be addressed urgently.

The ACPSEM Training, Education and Accreditation Program (TEAP) in Radiation Oncology Physics is well established in some jurisdictions with significant resources being provided and has been well supported by the Department of Health and Aging (DoHA) in Australia and the Department of Health in New Zealand. However, some jurisdictions have yet to realize the need to address the issues of ensuring the ongoing supply of trainee physicists for the radiation oncology physics workforce. A recent analysis ${ }^{4}$ suggests that for the next few years in Australia 30 new registrars need to enter the radiation oncology TEAP each year to ensure the workforce is adequately supplied with qualified radiation oncology physicists. 


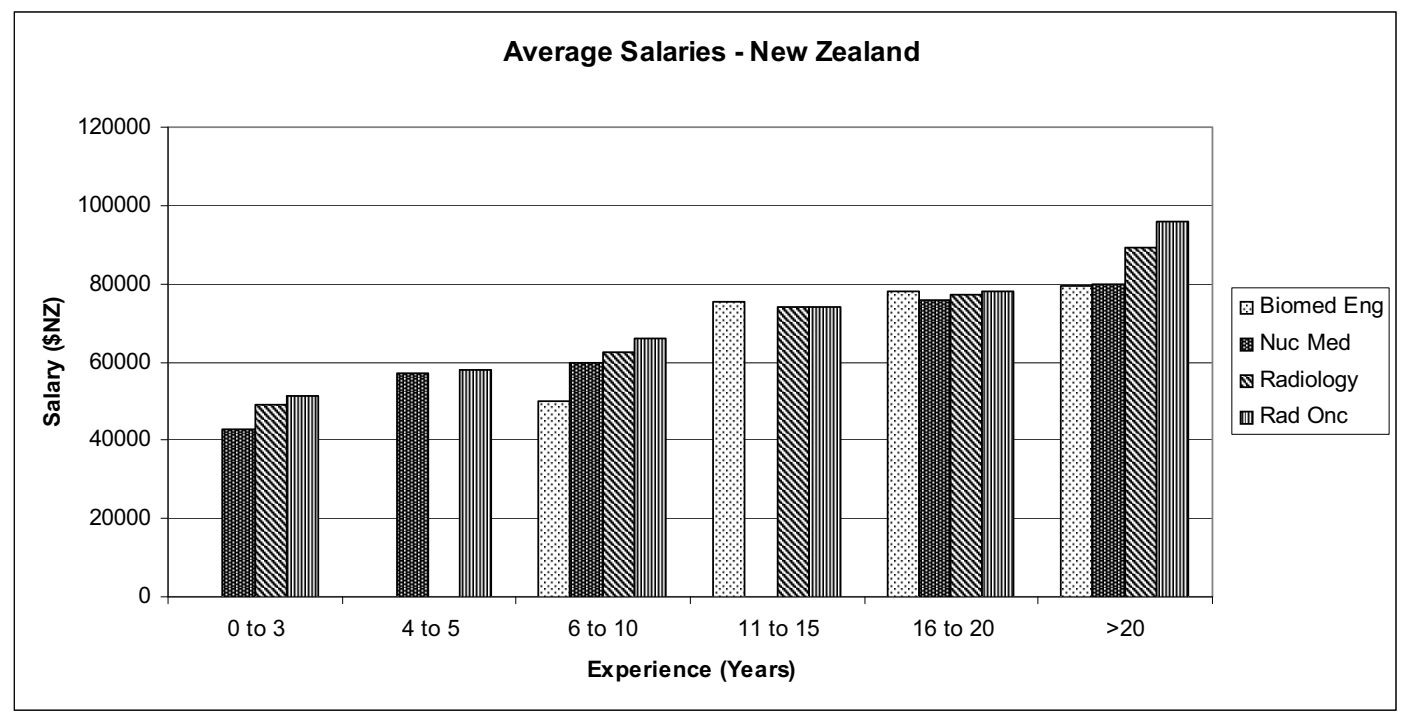

Figure 12. The average salaries of the various disciplines in New Zealand

Extrapolating this to New Zealand on a population basis indicates that six new registrars are required each year in that country. The estimates of the needs do not take into account the emergence of newer treatment techniques such as IGRT that require significantly more physics input and therefore increase the need for an enhanced workforce. Other factors such as young physicists leaving the workforce to have a family are also not taken into account. Modelling done by others ${ }^{5}$ has suggested that the number of registrars should be even higher.

\section{Radiology physics}

Western Australia and Queensland have established radiology quality assurance systems that have significant input from and oversight by radiology physicists and have the highest number of physicists per million population. Victoria is also moving in this way, but has among the lowest number of radiology physicists per million population, indicating that a training scheme must be established in the very near future if it is to be able to meet its requirements in the near future. The low numbers of radiology physicists in other jurisdictions must be addressed and further positions created. To meet the standard of 3.1 physicists per million population in Western Australia in other jurisdictions Australia would need about 65 radiology physicists and New Zealand about 13, whereas currently there are 27 and 9 EFT radiology physicist positions respectively in these countries. To reach the German standard, Australia would need about 134 and New Zealand about 27 qualified radiology physicists.

To meet the need to train radiology physicists for the future, it is vital that the TEAP in Radiology Physics is developed to the same extent as the TEAP in Radiation Oncology Physics. This will require significant government funding and a commitment by the jurisdictions to establish the physicist positions. There are significant logistic problems in establishing training in some jurisdictions as there is little or no capacity to train physicists.

\section{Nuclear medicine physics}

The number of nuclear medicine physicist positions varies considerably from jurisdiction to jurisdiction in the same way that the number of radiology physicist positions does. There is a demonstrable lack of nuclear medicine physicist positions in all jurisdictions. To reach the German standard there should be approximately 67 qualified nuclear medicine physicist positions in Australia and 13 in New Zealand, whereas currently there 31 and 1.5 EFT qualified nuclear medicine physicist positions respectively in those countries. With the increasing use of PET scanning which requires more significant physicist input than other nuclear medicine techniques, the need for nuclear medicine physicist positions is certainly going to be greater than 67 and 13.

To meet the need to train nuclear medicine physicists for the future, it is vital that the TEAP in nuclear medicine physics is also developed to the same extent as the TEAP in Radiation Oncology Physics. Again, this will require significant government funding and a commitment by the jurisdictions to establish the physicist positions.

\section{Physics cross-discipline matters}

Radiation oncology physicists tend to work within their own discipline. Of the 288 positions that involve radiation oncology, 245 were $100 \%$ EFT radiation oncology physics and 270 were at least $50 \%$ EFT radiation oncology physics.

However, a significant portion of the medical physics workforce works across more than just one of the three physics disciplines.

Of the 67 positions involving radiology physics, only 21 were $100 \%$ EFT radiology physics and only 35 involved at least $50 \%$ EFT radiology physics. Of the 79 positions involving nuclear medicine physics, only 27 were $100 \%$ EFT nuclear medicine physics positions and 42 involved more than 50\% EFT nuclear medicine physics.

33 positions involved both radiology physics and nuclear medicine physics. 24 of the radiation oncology positions also involved radiology and/or nuclear medicine 
physics. This indicates a need for a training program that covers a combination of radiation oncology physics, radiology physics and nuclear medicine physics to provide for those who will work in multiple disciplines.

Also, as imaging is becoming a more significant aspect of the work of the oncology physicist, it is important that those who provide funding support for the establishment and continued operation of the ACPSEM TEAPs recognize this nexus and cooperate in ensuring that the radiation, radiology and nuclear medicine TEAPs are properly funded and functioning.

\section{Biomedical engineering}

The inability to define and account for the entire biomedical engineering workforce makes it difficult to draw conclusions as easily as can be done for the medical physics workforce. However, attention should be given to the large variation in salaries paid in the different jurisdictions for the same level of experience.

\section{Disclaimer}

The views expressed in this article are those of the author and do not necessarily reflect the official position of the College.

\section{References}

1. Oliver, L., Fitchew, R. and Drew, J. Requirements for radiation oncology physics in Australia and New Zealand. Aust. Phys. \& Eng. Sci., 20, No. 1, 1-18, 2001.

2. Leetz, H. K., Eipper, H.H., Gfirtner, P. and Welker, K. DGMP-Bericht Nr. 17 Zur Personalsituation in der Medizinischen Strahlenphysik in Deutschland: Austwertung einer Umfrage. Deutsche Gesellschaft fur Medizinische Physik e.V., 2002.

3. Eudaldo, T. and Olsen K. The European Federation of Organisations for Medical Physics Policy Statement No 12 The Present Status of Medical Physics Education and Training in Europe. New Perspectives and EFOMP Recommendations, July 2002.

4. Oliver, L. Personal communication.

5. Drew, J. Personal communication. 